\title{
Manejo da densidade de plantas durante a produção de mudas em viveiro
}

\author{
Density management of plants during the seedling production in nursery
}

\author{
Júlio Cézar Tannure Faria', Dalila Araújo Lopes", Gustavo Bastos Lyra" ${ }^{\mathrm{III}}$, Hyrandir \\ Cabral de Melo ${ }^{\mathrm{IV}}$, Lucas Amaral de Melov
}

\section{Resumo}

O objetivo do estudo foi otimizar a densidade de plantas em canteiro durante a produção de mudas em tubetes. Para isso, o experimento foi conduzido por meio da produção de mudas seminais de um híbrido de Eucalyptus urophylla x Eucalyptus grandis, composto por sete tratamentos e quatro repetições de 70 plantas por parcela. Cada tratamento consistiu na redução da densidade de mudas no canteiro pela metade em diferentes momentos durante o processo de produção. As mudas foram produzidas em tubetes de polipropileno com $55 \mathrm{~cm}^{3}$ de capacidade volumétrica. As reduções de densidade foram realizadas aos 30 , $45,60,75,90,105$ ou 120 dias após a semeadura. A fim de ter subsídios para otimizar o manejo da densidade de plantas durante a produção de mudas, foram conduzidas determinações do índice de área foliar aos 100 dias após a semeadura e, foram realizadas avaliações das características altura da parte aérea, diâmetro do coleto, relação altura/diâmetro, massa seca da parte aérea, massa seca do sistema radicular, massa seca total, relação massa seca aérea/radicular e índice de Dickson de 20 plantas por parcela, ao fim do ciclo de produção, aos 120 dias. Com base nos resultados, verifica-se que a redução da densidade realizada em diferentes momentos altera as características de crescimento das mudas, e que, considerando um ciclo de produção de 120 dias, recomenda-se a redução da densidade pela metade entre os 60 e 75 dias após a semeadura, uma vez que para todas as características avaliadas, este foi o intervalo de tempo que propiciou melhores características às mudas produzidas.

Palavras-chave: Alternagem; Índice de área foliar; Otimização da produção; Qualidade de mudas

\begin{abstract}
The objective of the study was to optimize the seedling density during the seedling production. To do so, the experiment was conducted through the production of seedlings of a hybrid of Eucalyptus urophylla $\mathrm{x}$ Eucalyptus grandis, comprising seven treatments and four replicates of 70 plants per plot. Each treatment consisted of reducing the density of seedlings in the plot in half at different times during the production process. The seedlings were produced in polypropylene tubes with $55 \mathrm{~cm}^{3}$ of volumetric capacity. Density reductions were performed at $30,45,60,75,90,105$ or 120 days after sowing. In order to obtain subsidies to optimize the plant density management during the seedling production, leaf area index determinations were conducted at 100 days after sowing, and plant height, stem diameter, height/diameter, shoot dry mass, dry mass of roots, total dry mass, dry mass ratio of shoot/root dry mass and Dickson quality index of 20 plants per plot were evaluated at the end of the production cycle at 120 days. Based on the results, it is verified that the reduction of density at different times changes the growth characteristics of the seedlings, and considering a 120-day production cycle, it is recommended to reduce the density by half between 60 and 75 days after sowing, since for all characteristics evaluated, this was the time interval that provided better characteristics to the seedlings produced.
\end{abstract}

Keywords: Alternation; Leaf area index; Optimization of production; Seedling quality

Engenheiro Florestal, MSc., Doutorando do Programa de Pós-Graduação em Engenharia Florestal, Universidade Federal de Lavras, Caixa Postal 3037, CEP 37200-000, Lavras (MG), Brasil. jc.tannure@gmail.com (ORCID: 0000-0001-7081-3726)

II Engenheira Florestal, Mestranda do Programa de Pós-Graduação em Ciências Ambientais e Florestais, Universidade Federal Rural do Rio de Janeiro, Instituto de Florestas, BR 465, Km 07, CEP 23890-000, Seropédica (RJ), Brasil. dalilaraujo09@hotmail.com (ORCID: 0000-0003-3619-5391)

III Meteorologista, Dr., Professor do Departamento de Ciências Ambientais e Florestais, Universidade Federal Rural do Rio de Janeiro, Instituto de Florestas, BR 465, Km 07, CEP 23890-000, Seropédica (RJ), Brasil. Instituto de Florestas, BR 465, Km 07, CEP 23890-000, Seropédica (RJ), Brasil. gblyra@ufrrj.br (ORCID: 0000-0002-9882-7000)

IV Engenheiro Agrônomo, Dr., Professor do Departamento de Botânica, Universidade Federal de Goiás, Instituto de Ciências Biológicas, CEP 74001970, Goiânia (GO), Brasil. hyrandir@gmail.com (ORCID: 0000-0001-9546-2539)

Engenheiro Florestal, Dr., Professor do Departamento de Ciências Florestais, Universidade Federal de Lavras, Caixa Postal 3037, CEP 37200-000, Lavras (MG), Brasil. lucas.amaral@dcf.ufla.br (ORCID: 0000-0001-5219-9179) 


\section{Introdução}

A partir dos anos 2000, o crescimento da demanda por produtos florestais direcionou a área de silvicultura a desenvolver e aperfeiçoar técnicas que ampliem sua produtividade econômica/ ambiental (XAVIER; SILVA, 2010). No Brasil, a maior parte dos produtos de origem silvicultural é oriunda dos povoamentos florestais do gênero Eucalyptus. A grande escala de produção do Eucalyptus sp. na composição de povoamentos florestais no País ocorre devido ao crescimento das demandas nos setores industriais do segmento de papel e celulose, associado as suas características desejáveis de produção, como rápido crescimento, boa adaptabilidade às condições edafoclimáticas, que proporcionam ciclos de corte curtos quando comparado com outras espécies madeireiras (BARRETTO et al., 2007).

Neste contexto, um dos principais critérios que garante o êxito de um povoamento florestal é a qualidade das mudas e seu posterior desempenho no campo (ARAÚJO; NAVROSKU; SCHORN, 2018). Na fase de crescimento em viveiro, as mudas apresentam aumento das necessidades nutricionais e de consumo de água, devido à aceleração do seu metabolismo. Ocorre também maior demanda por radiação solar, que resulta na necessidade de modificações no manejo conduzido durante o processo de produção (WENDLING; DUTRA, 2010). A densidade de mudas no viveiro é considerada uma importante prática de manejo para otimizar o espaço no ambiente. Além disso, exerce influências diretamente relacionadas ao crescimento e arquitetura das mudas, apresentando diferentes padrões de acordo com os espaçamentos (ATAÍDE et al., 2010), o qual contribui para a distribuição da área foliar e, consequentemente, como esta interceptará (STEWART et al., 2003; WENDLING; DUTRA, 2010) e traduzirá (CHEN; CHORY; FANKHAUSER, 2004) a radiação solar incidente.

Uma das técnicas que contribui no aumento e na quantidade de energia captada por unidade de área e de tempo é a modificação do arranjo das mudas, também chamado de alternagem, consistindo em encurtar o tempo para que a cultura intercepte o máximo da radiação solar incidente por meio do maior índice de área foliar (KUNZ et al., 2007). Um dos principais objetivos dessa técnica é reduzir a competição entre as mudas, aumentando o espaçamento entre as mesmas e melhorando assim a qualidade no produto final (LIMA et al., 2008). De acordo com Davide et al. (2015), a redução da densidade de mudas na bandeja reduz o crescimento em altura das mudas, aumenta o crescimento em diâmetro, permite melhor aeração, reduz o risco de contaminação por fungos patogênicos, possibilita melhor irrigação, aplicação de adubos e insolação das mudas.

Em condições ótimas de disponibilidade de água e nutrientes, os padrões de crescimento vegetal ocorrem em função da intensidade e qualidade da radiação global que atua como sinal à fotomorfogênese e à radiação fotossinteticamente ativa (RFA), visto que esta determina as taxas fotossintéticas e, assim, a produção de biomassa (CARON et al., 2012). A eficiência do uso da RFA (EUR) pelas espécies vegetais depende da quantidade de RFA interceptada pelas folhas e que é convertida efetivamente em biomassa (MONTEITH, 1977). Um dos fatores que determina a EUR é o índice de área foliar - IAF (razão entre a área foliar e a área de solo disponível para a mesma), que depende da área foliar e da densidade de plantas. Como na maior parte dos ambientes para a produção de mudas de espécies florestais observam-se alterações na disponibilidade da RFA e a alternagem modifica a densidade de plantas, a análise do IAF apresenta potencial para subsidiar a definição das características desejáveis das mudas, assim como a avaliação em si das características relacionadas ao crescimento das plantas.

Além disso, a avaliação de aspectos econômicos de qualquer atividade de produção é importante pois envolve o uso de técnicas e critérios que analisem e comparemos custos, a fim de decidir se este é viável ou não de ser implementado para determinada atividade. Essa avaliação é importante para a dinamização do processo de produção de mudas que objetivam produzir grandes quantidades de mudas no padrão de qualidade exigido e com um custo competitivo para o mercado (DIAS et al., 2011).

Dessa forma, objetivou-se otimizar a densidade de plantas em canteiro durante a produção de mudas em tubetes, com base em modificações biométricas em função da redução de densidade 
realizada em diferentes momentos durante o ciclo de produção. Testou-se a hipótese de que a redução da densidade espacial realizada em diferentes momentos altera o Índice de Área Foliar, as características de crescimento e os Índices de qualidade das mudas. Espera-se, com o presente trabalho, contribuir para o entendimento da técnica de manejo da alternagem para melhorar a otimização da mesma e garantir ganhos significativos durante o ciclo de crescimento de mudas em Eucalyptus.

\section{Material e métodos}

O experimento foi conduzido no Viveiro Florestal da Universidade Federal Rural do Rio de Janeiro, localizado no Instituto de Florestas (2275’73” S, 4369'63” W), no município de Seropédica - RJ, no período de agosto a dezembro. Segundo a classificação de Köppen, o clima da região é do tipo Aw, Tropical com chuvas de verão. As chuvas na região se concentram entre novembro e março, com precipitação anual média de $1213 \mathrm{~mm}$ e temperatura do ar média anual de $23,9^{\circ} \mathrm{C}$ (CARVALHO et al., 2006).

Foram utilizadas para produção de mudas, sementes de um híbrido de Eucalyptus urophylla $\mathrm{x}$ Eucalyptus grandis, adquiridas do Instituto de Pesquisas e Estudos Florestais (IPEF). Como recipientes, foram utilizados tubetes de polipropileno com $55 \mathrm{~cm}^{3}$ de capacidade e bandejas de polipropileno para suporte destes, em densidade inicial de 560 mudas por $\mathrm{m}^{2}$, em que quatro bandejas ocupam o espaço de $1 \mathrm{~m}^{2}$.

O substrato utilizado para a semeadura foi obtido a partir de uma mistura, em base volumétrica, de $10 \%$ de vermiculita de granulometria média, $20 \%$ de casca de arroz carbonizada, $30 \%$ de esterco de curral curtido e $40 \%$ de substrato comercial da marca MecPlant ${ }^{\oplus}$. No momento da mistura dos componentes, foram adicionados $1 \mathrm{~kg}$ de superfosfato simples $+3,5 \mathrm{~kg}$ de NPK 06:30:06 por $\mathrm{m}^{3}$ de substrato, conforme recomendação de Davide e Silva (2008).

Depois de preparado o substrato, procedeu-se à semeadura manual, colocando-se em torno de quatro sementes por recipiente. Após 14 dias da germinação, realizou-se um raleio por meio do corte das mudas excedentes, de modo a deixar como remanescente a planta mais centralizada no tubete e com melhor crescimento da parte aérea. Durante os 21 primeiros dias após a semeadura, as mudas permaneceram em ambiente natural, apenas sob proteção de tela de sombrite, com malha de $50 \%$ de sombreamento, com o intuito de evitar que as sementes e plântulas fossem injuriadas por intempéries meteorológicas.

Durante todo o processo de produção, as mudas foram irrigadas quatro vezes ao dia, às $9 \mathrm{~h} 30,12 \mathrm{~h}, 14 \mathrm{~h}$ e $16 \mathrm{~h} 30$, por sistema de irrigação com microaspersores, sendo um total de $10 \mathrm{~mm}$ diários, sendo cessada a irrigação em dias chuvosos.

Aos 30 dias após a semeadura, o experimento foi instalado em um delineamento inteiramente casualizado (DIC), constituído por sete tratamentos, em quatro repetições de 70 plantas por parcela (bandeja). Cada tratamento consistiu da redução da densidade das mudas pela metade (de 560 para 280 mudas por $\mathrm{m}^{2}$ ) em diferentes momentos durante o processo de produção. Aos 30 (T1), 45 (T2), 60 (T3), 75 (T4), 90 (T5), 105 (T6) e 120 (T7) dias após a semeadura foram os tempos nos quais ocorreu a redução pela metade da densidade de plantas nas bandejas. Considerou-se T7 como o último tratamento, pois se verificou que as mudas apresentavam características que remetiam ao fim do ciclo de produção aos 120 dias após a semeadura.

Aos 60 e 90 dias após a semeadura foram feitas adubações de cobertura com monoamônio fosfato (MAP) e cloreto de potássio (KCl) na proporção de 0,1 g de MAP e 0,01 g de KCl por muda, diluídos em $10 \mathrm{ml}$ de água (DAVIDE; SILVA, 2008).

Quando as mudas alcançaram 100 dias após a semeadura, foram conduzidas determinações do Índice de Área Foliar (IAF) em cada tratamento. Nesse momento, foram considerados seis tratamentos, pois as mudas do T6 e T7 estavam sob as mesmas condições por ainda não terem passado pela redução da densidade.

O IAF (relação entre a área total de folhas por planta e a área de superfície disponível 
para a mesma) foi obtido de forma não destrutiva com auxílio de um ceptômetro (AccuPAR LP80, Decagon Devices, Inc.). O ceptômetro possibilita realizar medidas da densidade de fluxo de fótons fotossintéticos (DFFF) acima $\left(\mathrm{DFFF}_{\mathrm{a}}\right)$ e abaixo $\left(\mathrm{DFFF}_{\mathrm{in}}\right)$ do dossel. Baseado nessas medidas e em parâmetros relacionados à arquitetura do dossel (distribuição da área foliar) e à radiação solar (ângulo zenital e a fração da irradiância solar direta e irradiância proveniente de outras fontes, como difusa ou mesmo refletida por outras superfícies), o ceptômetro estima o IAF. Todas as medidas foram realizadas em um intervalo de dez minutos, iniciando às $12 \mathrm{~h}$, para evitar influência de outros fatores nas medidas da DFFF (como por exemplo, ângulo de elevação solar).

Realizaram-se medidas com o ceptômetro em seis diferentes posições dentro do dossel de cada umas das quatro repetições (bandejas). As posições foram definidas em relação ao centro da bandeja, equidistante nos dois lados, e da seguinte forma: próximo à borda, intermediário e próximo ao centro. Após as medidas, foram registradas as médias da $\mathrm{DFFF}_{\mathrm{a}}$ e da $\mathrm{DFFF}_{\text {in }} \mathrm{e}$ estimado o IAF por bandeja, calculando-se a média das seis medidas.

Ao fim do ciclo de produção, aos 120 dias após a semeadura, foram realizadas avaliações das seguintes características biométricas: altura da parte aérea (H), diâmetro do coleto (DC), relação entre altura e o diâmetro do coleto (H/DC), massa seca da parte aérea (MSPA), massa seca do sistema radicular (MSR), massa seca total (MST), relação entre massa seca da parte aérea e massa seca do sistema radicular (RMSPAR) e Índice de Qualidade de Dickson (IQD) de 20 plantas por parcela.

O diâmetro do coleto foi medido com o auxílio de um paquímetro digital e a altura da parte aérea com régua milimetrada, tomando-se como padrão a gema terminal (meristema apical). Para a obtenção da massa seca da parte aérea e da massa seca do sistema radicular foi realizada a pesagem das partes vegetais, em separado, após a secagem destas em estufa de circulação de ar forçada a $70^{\circ} \mathrm{C}$, por cerca de aproximadamente $72 \mathrm{~h}$. O Índice de Qualidade de Dickson foi obtido pela Equação 1 (DICKSON; LEAF; HOSNER, 1960):

$$
\mathrm{IQD}=\frac{\operatorname{MST}_{(\mathrm{g})}}{\mathrm{H}_{(\mathrm{cm})} / \mathrm{DC}_{(\mathrm{mm})}+\mathrm{MSPA}_{(\mathrm{g})} / \mathrm{MSR}_{(\mathrm{g})}}
$$

Em que, $\operatorname{MST}_{(\mathrm{g})}=$ Massa seca total; $\mathrm{H}_{(\mathrm{cm})}=$ Altura da parte aérea; $\mathrm{DC}_{(\mathrm{mm})}=$ Diâmetro do coleto; $\mathrm{MSPA}_{(\mathrm{g})}=\mathrm{Massa}$ seca da parte aérea; $\mathrm{MSR}_{(\mathrm{g})}=$ Massa seca do sistema radicular.

Os dados mensurados foram submetidos ao teste de Hartley $(P<0,05)$ e Shapiro-Wilk $(P<0,05)$, a fim de verificar a homogeneidade das variâncias e a distribuição normal dos dados, respectivamente. Em seguida, procedeu-se à análise estatística (ANOVA) pelo teste $\mathrm{F}$ e a comparação pelo teste Scott-Knott em nível de 5\% de probabilidade de erro, por meio do software SISVAR $^{\circledast}$ (FERREIRA, 2011). Além disso, como forma de ter subsídios para otimizar o manejo da densidade de plantas durante a produção de mudas, os dados obtidos para as mudas de eucalipto, aos 120 dias, foram submetidos à análise de regressão por meio do software SISVAR ${ }^{\circledR}$, e sua apresentação gráfica pelo aplicativo SigmaPlot ${ }^{\circledR}$.

\section{Resultados e discussão}

Pela análise de variância ANOVA $(\mathrm{P}<0,05)$, os Índices de Área Foliar (IAF) entre os tratamentos apresentaram diferenças estatísticas significativas, com médias entre 1,62 $( \pm$ $0,20)$ (T5) e $1,95( \pm 0,13)$ (T3). Mudas do tratamento T5 apresentaram diferenças estatísticas significativas (teste $\mathrm{Scott}-\mathrm{Knott}, \mathrm{P}<0,05$ ) em relação às mudas dos demais tratamentos, com $\mathrm{o}$ menor IAF (Tabela 1). 


\section{Tabela 1 - Índice de Área Foliar (IAF) das mudas de Eucalyptus urophylla x Eucalyptus grandis, aos 100 dias após a semeadura, em função do momento em que foi realizada a redução da densidade de mudas.}

Table 1 - Foliar Area Index (IAF) of Eucalyptus urophylla x Eucalyptus grandis seedlings at 100 days after sowing, according to the time when the seedling density reduction was performed.

\begin{tabular}{lc}
\hline \multicolumn{1}{c}{ Tratamentos } & IAF \\
\hline T1 (Densidade reduzida aos $\mathbf{3 0}$ dias) & $1,87 \mathrm{a}^{*}$ \\
T2 (Densidade reduzida aos $\mathbf{4 5}$ dias) & $1,84 \mathrm{a}$ \\
T3 (Densidade reduzida aos 60 dias) & $1,95 \mathrm{a}$ \\
T4 (Densidade reduzida aos 75 dias) & $1,80 \mathrm{a}$ \\
T5 (Densidade reduzida aos 90 dias) & $1,62 \mathrm{~b}$ \\
T6 (Densidade seria reduzida aos 105 dias) & $1,80 \mathrm{a}$ \\
\hline CV (\%) & 10,01 \\
\hline
\end{tabular}

${ }^{*}$ Médias seguidas da mesma letra não diferem estatisticamente entre si pelo teste ScottKnott $(P<0,05)$.

É possível verificar (Tabela 1), que ao sofrerem redução da densidade, consequentemente redução do sombreamento mútuo e maior exposição solar, as mudas apresentam redução do IAF, mas que com o tempo, este parâmetro é normalizado e volta aos valores encontrados antes desta prática silvicultural. Este resultado pode ser constatado com os dados do tratamento com redução da densidade aos 90 dias (T5), comparado com o resultado de mudas que ainda não haviam passado pela redução da densidade (T6) e de mudas que haviam tido a redução da densidade há pelo menos 25 dias antes da avaliação (T4).

Verifica-se que dez dias são insuficientes para que as mudas retornem aos valores de IAF encontrados anteriormente à redução da densidade. Em contrapartida, nota-se que 25 dias são suficientes para que as mudas se aclimatem à nova condição e retornem o IAF aos valores encontrados antes da redução da densidade pela metade. Desta forma, considerando que a redução da densidade é prática silvicultural necessária a fim de melhorar a qualidade de mudas (DAVIDE et al., 2015), deve-se tomar o cuidado para que haja tempo suficiente entre sua realização e aclimatação das mudas à nova condição, principalmente, de maior exposição à radiação solar.

$\mathrm{O}$ retorno do IAF a padrões 25 dias anteriores à redução da densidade de plantas indica aumento ou em número de folhas e ou em expansão foliar, em resposta à maior incidência de radiação luminosa após a redução da densidade das plantas, o que por sua vez, é um indicativo de uma muda de melhor qualidade em função de maior potencialidade quanto ao aparato fotossintético. $\mathrm{O}$ resultado evidenciado por este trabalho, com incremento do aparato fotossintético pela área foliar, normalmente decorrente do aumento de número de folhas por planta, é de comum ocorrência em outras espécies, assim como observado no hibrido de Brassica napus L. (Hyola 61) em função do aumento do espaçamento entre linhas (CHAVARRIA et al., 2011).

A redução da densidade de plantas em uma área pode levar à formação de novas folhas ou resultar em maior crescimento das folhas ainda imaturas das plantas remanescentes, uma vez que tanto a intensidade quanto a qualidade de radiação são modificadas no ambiente, favorecendo o processo fotossintético, e consequentemente aumentando a produção de fotoassimilados necessários ao desenvolvimento das novas folhas (COLOMBO et al., 2016). Adicionalmente, a morfogênese foliar também é regulada pelos fotorreceptores fitocromos, fototropinas e criptocromos (WESTON et al., 2000; FRAGOSO et al., 2017), os quais, por sua vez, têm ação modificada pela alteração da intensidade e qualidade da radiação que pode ocorrer em função da diminuição da densidade de 
plantas na área de produção de mudas ou cultivo.

Com relação à altura da parte aérea, as mudas de Eucalyptus urophylla x Eucalyptus grandis apresentaram diferenças estatísticas significativas $(\mathrm{P}<0,05)$ entre os tratamentos estudados, com valores médios variando de $23,51( \pm 1,98)$ a $39,48( \pm 2,43) \mathrm{cm}$. O tratamento T7 apresentou a maior média em altura das mudas, sendo estatisticamente superior aos demais tratamentos (Tabela 2).

Tabela 2 - Altura da parte aérea (H), diâmetro do coleto (DC), relação altura/diâmetro (H/ DC) e índice de qualidade de Dickson (IQD) das mudas de Eucalyptus urophylla $\mathbf{x}$ Eucalyptus grandis, aos 120 dias após a semeadura, em função do momento em que foi realizada a redução da densidade de mudas.

Table 2 - Shoot Height (H), collet diameter (DC), ratio height/diameter (H/DC) and Dickson quality index (IQD) of Eucalyptus urophylla x Eucalyptus grandis seedlings at 120 days after sowing, according to the moment when the seedling density reduction was carried out.

\begin{tabular}{lcccc}
\hline \multicolumn{1}{c}{ Tratamentos } & H $(\mathbf{c m})$ & DC $(\mathbf{m m})$ & H/DC & IQD \\
\hline T1 (Densidade reduzida aos 30 dias) & $24,81 \mathrm{~d}^{*}$ & $2,51 \mathrm{a}$ & $9,85 \mathrm{~d}$ & $0,107 \mathrm{a}$ \\
T2 (Densidade reduzida aos 45 dias) & $23,51 \mathrm{~d}$ & $2,19 \mathrm{~b}$ & $10,73 \mathrm{~d}$ & $0,099 \mathrm{a}$ \\
T3 (Densidade reduzida aos 60 dias) & $25,97 \mathrm{~d}$ & $2,28 \mathrm{~b}$ & $11,38 \mathrm{~d}$ & $0,107 \mathrm{a}$ \\
T4 (Densidade reduzida aos 75 dias) & $28,95 \mathrm{c}$ & $2,18 \mathrm{~b}$ & $13,24 \mathrm{c}$ & $0,100 \mathrm{a}$ \\
T5 (Densidade reduzida aos 90 dias) & $32,49 \mathrm{~b}$ & $2,14 \mathrm{~b}$ & $15,20 \mathrm{~b}$ & $0,085 \mathrm{~b}$ \\
T6 (Densidade reduzida aos 105 dias) & $34,92 \mathrm{~b}$ & $2,13 \mathrm{~b}$ & $16,35 \mathrm{~b}$ & $0,081 \mathrm{~b}$ \\
T7 (Densidade reduzida aos 120 dias) & $39,48 \mathrm{a}$ & $2,02 \mathrm{~b}$ & $19,54 \mathrm{a}$ & $0,079 \mathrm{~b}$ \\
\hline CV (\%) & 6,71 & 4,00 & 13,76 & 12,90 \\
\hline
\end{tabular}

${ }^{*}$ Médias seguidas da mesma letra, na coluna, não diferem estatisticamente entre si pelo teste Scott-Knott $(P<0,05)$.

A alternagem influenciou diretamente no crescimento da altura da parte aérea das mudas de eucalipto. À medida que a alternagem foi realizada próxima ao final do ciclo de produção, os tratamentos apresentaram mudas com resultados médios maiores em altura. A alternagem realizada nos tratamentos T1, T2 e T3 resultou nos menores valores médios, o que, nesse caso, não significa mudas de menor qualidade (Figura 1).

A regulação fotomorfogênica da altura do caule já é bastante conhecida em estudos que envolvem a participação dos fitocromos. A razão das bandas espectrais da radiação solar V:VE (Vermelho: Vermelho Extremo) é considerada o fator mais importante para determinar a ação dos fitocromos, e esta razão varia ao longo do dia de 1.05 a 1.25 em condição de pleno sol, mas pode variar de 0.05 a 1.15 em condição de sombra cujo anteparo à luz são as folhas (SMITH, 1994), tal qual é o fator de sombreamento em alta densidade de plantas. O fitocromo B (phyB) é considerado o fotorreceptor mais importante à regulação do alongamento caulinar, uma vez que quando ativo desencadeia mecanismos de inativação ou de destruição dos PIFs (Fatores de Interação de Fitocromos), os quais atuam como fatores de transcrição gênica que estimulam a transcrição de genes relacionados ao alongamento de células caulinares (LEIVAR; MONTE, 2014). E uma vez que o phyB tem ação mais efetiva em condição não sombreada, com alta razão V:VE, e também com alta incidência luminosa (CHEN; CHORY; FANKHAUSER, 2004), e o fato de um ambiente, como o deste experimento, está com alta densidade de plantas e com muitas folhas autossombreadas dificulta a ação deste fotorreceptor, e portanto, propicia um alongamento maior dos caules, tal qual revelado pela maior altura das mudas em que a redução da densidade de plantas foi mais tardia. 
Figura 1 - Altura da parte aérea e diâmetro do coleto de mudas de Eucalyptus urophylla x Eucalyptus grandis, aos 120 dias após a semeadura, em função do momento em que foi realizada a redução da densidade de mudas.

Figure 1 - Shoot height and collet diameter of Eucalyptus urophylla x Eucalyptus grandis, at 120 days after sowing, according to the time when the seedling density reduction was performed.

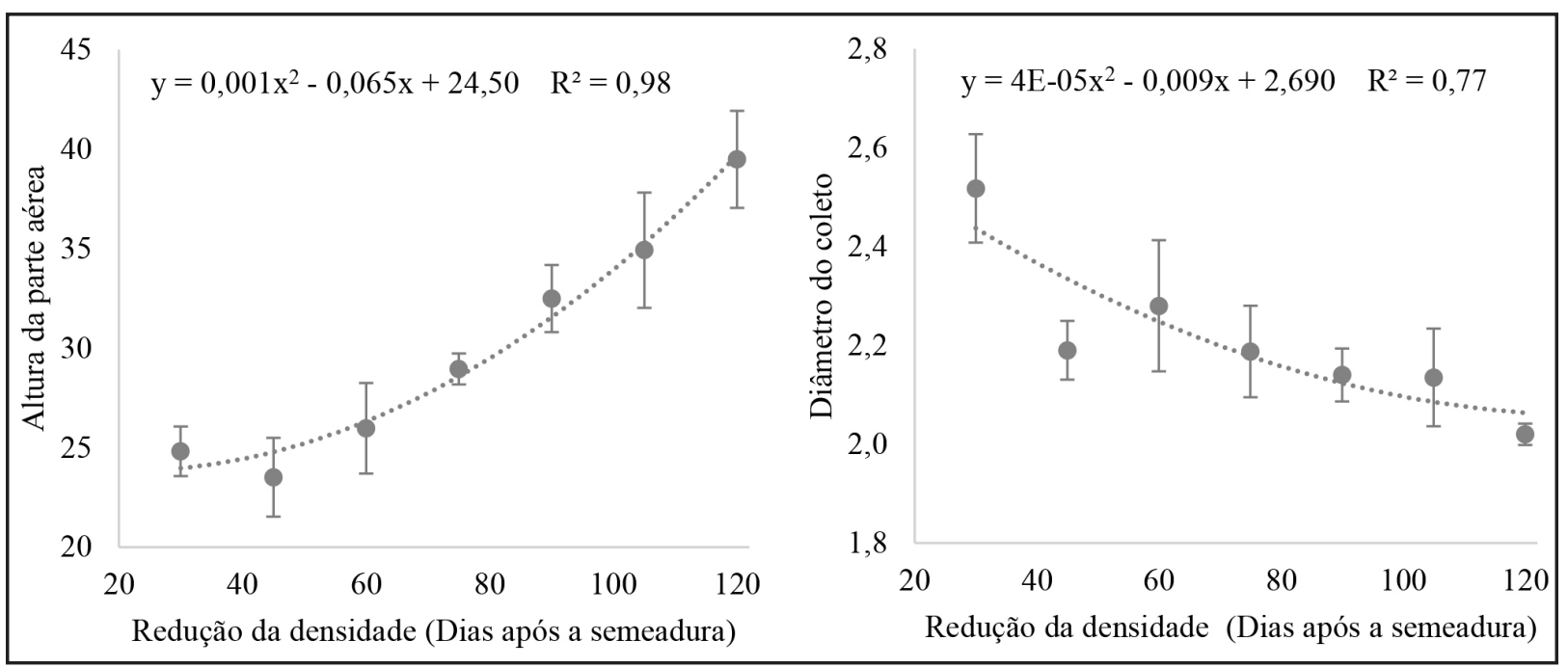

Fonte: Autores (2019)

Para verificação da qualidade de mudas de espécies florestais, Gonçalves et al. (2000) recomendam limites de altura entre 20 e $35 \mathrm{~cm}$, valor esse principalmente relacionado a mudas de eucalipto produzidas em tubetes de $55 \mathrm{~cm}^{3}$. Baseado na faixa de qualidade recomendada para a altura, no presente estudo apenas o tratamento T7 obteve resultado fora do padrão de qualidade, o que pode caracterizar uma muda estiolada, devido ao longo período em que as mudas permaneceram na densidade inicial.

A característica morfológica diâmetro do coleto das mudas de Eucalyptus urophylla x Eucalyptus grandis variou entre $2,02( \pm 0,02)$ a $2,51( \pm 0,10) \mathrm{mm}$. O tratamento T1 apresentou mudas com maior média para essa característica, e diferiu estatisticamente dos demais tratamentos (Tabela 2).

$\mathrm{O}$ diâmetro do coleto apresentou resposta inversamente proporcional ao crescimento em altura da parte aérea das mudas, com redução dos seus valores médios à medida que a alternagem foi realizada próxima ao fim do ciclo de produção (Figura 1).

De acordo com Wendling e Dutra (2010), o diâmetro do coleto é uma característica morfológica que indica a capacidade de sobrevivência das mudas no campo, e deve ser maior que $2 \mathrm{~mm}$, valor este também utilizado como referência para mudas de eucalipto produzidas em tubetes de $55 \mathrm{~cm}^{3}$. No presente estudo, todos os tratamentos obtiveram resultados superiores a $2 \mathrm{~mm}$, o que indicou boa qualidade em diâmetro das mudas de Eucalyptus urophylla x Eucalyptus grandis, porém, conforme verificado pelos resultados, espera-se que mudas alternadas mais precocemente atinjam os valores ditos mínimos, também mais precocemente.

Quando foi analisada a relação entre a altura da parte aérea e o diâmetro do coleto (H/DC), os valores médios das mudas de Eucalyptus urophylla x Eucalyptus grandis variaram entre 19,54 e 9,85, sendo esses valores superiores aos considerados ideais por Carneiro (1995), que indica valores de $\mathrm{H} / \mathrm{DC}$ variando entre 5,4 e 8,1, sendo esse intervalo responsável por expressar o balanceamento de crescimento entre ambas características.

$\mathrm{Na}$ literatura observa-se discordância na definição do valor ideal para a H/DC, sendo que o mesmo pode variar de acordo com a espécie, tipo e proporção de substrato, volume do recipiente, adubação e idade de avaliação das mudas (SOUZA et al., 2010; SPERANDIO et al., 
2011; PETTER et al., 2012; GOMES et al., 2013; DELARMELINA et al., 2015).

De acordo com Gonçalves et al. (2000), quanto menor a relação altura/diâmetro do coleto, num mesmo lote de mudas, melhor será a qualidade da muda, pois esta relação reflete quão robusta está a planta e leva a maiores percentuais de sobrevivência e crescimento em campo. No presente estudo, mudas do tratamento T1 foram as que apresentaram os menores valores médios dessa relação, porém, não diferindo estatisticamente dos tratamentos T2 e T3.

Com relação ao Índice de Qualidade de Dickson, os tratamentos T1, T2, T3 e T4 apresentaram os maiores valores médios, sendo estatisticamente similares. Segundo Aguiar et al. (2011), o IQD é um indicador satisfatório de qualidade, por considerar a robustez e o equilíbrio da distribuição da biomassa na muda, e permite agrupar os resultados de várias características importantes empregadas para avaliação da qualidade das mudas. De acordo com Reis et al. (2011), quanto maior for o valor de IQD, melhor será a qualidade da muda. No entanto, mais uma vez vale ressaltar que a interpretação dos dados de IQD só deve ser levada em consideração se as características que o compõem estiverem dentro dos valores considerados aceitáveis para mudas de espécies florestais, ressaltando ainda que estes valores são dependentes da espécie, do tipo e tamanho de recipiente e da idade da muda (SAIDELLES et al., 2009; TRAZZI et al., 2012; CALDEIRA et al., 2013; FARIA et al., 2013).

No presente estudo, os menores valores para o IQD foram encontrados em mudas dos tratamentos T5, T6 e T7, indicando assim que a redução da densidade feita em momentos mais próximos à expedição das mudas pode não ser aconselhável pelo fato de não haver tempo suficiente para induzir melhoria na qualidade das mudas (Tabela 2). Pela Figura 2 é possível verificar que em mudas alternadas mais precocemente, o IQD foi maior, enquanto a relação $\mathrm{H} / \mathrm{DC}$ foi menor, refletindo mudas de melhor qualidade.

Figura 2 - Relação H/DC e IQD de mudas de Eucalyptus urophylla x Eucalyptus grandis, aos 120 dias após a semeadura, em função do momento em que foi realizada a redução da densidade de mudas.

Figure 2 - Ratio H/DC and IQD ratio of Eucalyptus urophylla $\mathrm{x}$ Eucalyptus grandis seedlings, at 120 days after sowing, according to the moment when the seedling density reduction was performed.

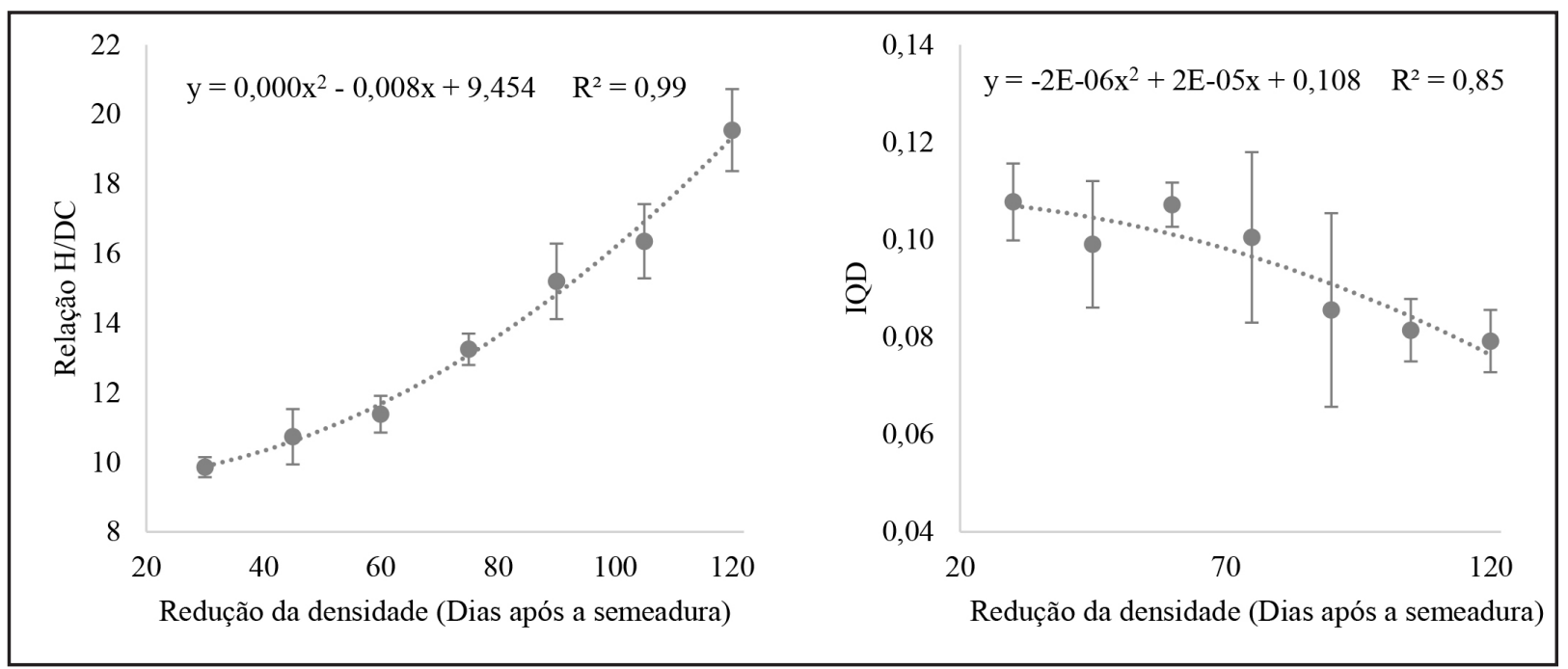

Fonte: Autores (2019)

Pelos resultados apresentados na Figura 2, pode-se inferir que o tratamento em que as mudas foram alternadas aos 60 dias após a semeadura (T3) é o mais aconselhável, uma vez que apresenta mudas com relação H/DC ainda baixa, quando comparadas às mudas alternadas mais tardiamente, além das mudas do T3 apresentarem IQD satisfatoriamente alto, quando comparadas às mudas alternadas mais precocemente. Resultados semelhantes são encontrados no estudo de Ataíde et al. 
(2010), os quais obtiveram os melhores crescimentos em diferentes características morfológicas em mudas de eucaliptos aos 55 dias utilizando o mesmo sistema de redução da densidade do presente estudo.

As características morfológicas massa seca da parte aérea, massa seca radicular, massa seca total e relação massa seca da parte aérea/raiz das mudas de Eucalyptus urophylla x Eucalyptus grandis não apresentaram diferenças significativas entre os tratamentos (Tabela 3).

Tabela 3 - Massa seca da parte aérea (MSPA), massa seca radicular (MSR), massa seca total (MST) e relação massa seca da parte aérea/raiz (RMSPAR) das mudas de Eucalyptus urophylla x Eucalyptus grandis aos 120 dias após a semeadura, em função do momento em que foi realizada a redução da densidade de mudas.

Table 3 - Shoot dry mass (MSPA), root system dry mass (MSR), total dry mass (MST), ratio between shoot dry mass and root system dry mass (RMSPAR) of Eucalyptus urophylla $\mathrm{x}$ Eucalyptus grandis seedlings at 120 days after sowing, according to the moment when the seedling density reduction was carried out.

\begin{tabular}{ccccc}
\hline Tratamentos & MSPA $(\mathbf{g})$ & MSR $(\mathbf{g})$ & MST $(\mathbf{g})$ & RMSPAR \\
\hline T1 (Densidade reduzida aos 30 dias) & $1,306 \mathrm{a}^{*}$ & $0,272 \mathrm{a}$ & $1,578 \mathrm{a}$ & $4,792 \mathrm{a}$ \\
T2 (Densidade reduzida aos 45 dias) & $1,410 \mathrm{a}$ & $0,236 \mathrm{a}$ & $1,647 \mathrm{a}$ & $6,003 \mathrm{a}$ \\
T3 (Densidade reduzida aos 60 dias) & $1,458 \mathrm{a}$ & $0,295 \mathrm{a}$ & $1,754 \mathrm{a}$ & $4,993 \mathrm{a}$ \\
T4 (Densidade reduzida aos 75 dias) & $1,481 \mathrm{a}$ & $0,318 \mathrm{a}$ & $1,800 \mathrm{a}$ & $4,736 \mathrm{a}$ \\
T5 (Densidade reduzida aos 90 dias) & $1,304 \mathrm{a}$ & $0,326 \mathrm{a}$ & $1,630 \mathrm{a}$ & $4,047 \mathrm{a}$ \\
T6 (Densidade reduzida aos 105 dias) & $1,436 \mathrm{a}$ & $0,296 \mathrm{a}$ & $1,732 \mathrm{a}$ & $4,949 \mathrm{a}$ \\
T7 (Densidade reduzida aos 120 dias) & $1,618 \mathrm{a}$ & $0,322 \mathrm{a}$ & $1,940 \mathrm{a}$ & $5,052 \mathrm{a}$ \\
\hline CV (\%) & 9,70 & 16,37 & 10,05 & 13,08 \\
\hline
\end{tabular}

*Médias seguidas da mesma letra, na coluna, não diferem estatisticamente entre si pelo teste ScottKnott $(P<0,05)$.

Avaliando a massa seca da parte aérea (MSPA) e radicular (MSR), Araújo, Navrosku e Schorn (2018) concluíram que o aumento nos valores destas características é importante para o suporte da biomassa verde produzida pelas mudas. Ressaltou ainda que os valores da MSPA e MSR são influenciados pela qualidade das sementes, pelo tipo e proporção do substrato (componentes físico, químico e biológico) e pelo manejo das mudas no viveiro, além de outros aspectos, como volume do recipiente.

O fato de não ter ocorrido diferença em massa seca da parte aérea entre as plantas dos diferentes tratamentos, mas ocorrer diferença em altura das plantas em função das datas de redução de densidade de mudas indica que as plantas autossombreadas por períodos mais longos estavam com maior altura, não em função de maior acúmulo de fotoassimilados, mas em decorrência da condição de radiação a que estavam expostas. Como observado, quanto maior a altura do caule, menor era o diâmetro do coleto, o que evidencia um padrão de crescimento indesejado à maior qualidade das mudas, tal qual considerado pelo índice de qualidade de Dickson (IQD).

Com base nos resultados avaliados e de acordo com Araújo, Navrosku e Schorn (2018), uma densidade maior de mudas no viveiro influencia na competição por espaço de crescimento, que interfere principalmente na capacidade de assimilar luz. No presente estudo foi possível avaliar que a alternagem influenciou diretamente nas características morfológicas altura da parte aérea, diâmetro do coleto, relação H/DC, IQD e IAF, sendo uma técnica indicada ao viveirista quando se deseja 
manejar as mudas com maior precisão antes de serem levadas a campo.

Além disso, é importante analisar as questões econômicas para o melhor planejamento, organização e definição das atividades nas etapas de produção de mudas (DIAS et al., 2011). No início do processo de produção é interessante manter as mudas mais adensadas, principalmente por dois fatores. O primeiro é relacionado à melhor utilização do espaço do viveiro, uma vez que mais mudas podem ser colocadas em uma mesma área se estas estiverem mais adensadas. Ao realizar a redução da densidade de mudas, conforme feito neste trabalho o espaço necessário para comportar o mesmo número de mudas é dobrado, o que acarreta em elevação dos custos de produção (ATAÍDE et al., 2010). O segundo ponto é que no início do processo de produção de mudas de qualquer espécie, o crescimento em altura é favorecido pela maior densidade na bandeja, conforme relatado por José, Davide e Oliveira (2005), o que auxilia na redução do ciclo de produção, desde que controlados os fatores que causam redução da qualidade de mudas, tais como o estiolamento.

Avaliando diferentes características morfológicas de mudas de Eucalyptus grandis, Reis et al. (2008) afirmam que o correto arranjo entre as mudas no viveiro proporciona distribuição mais uniforme do crescimento e, consequentemente, leva as mudas a terem melhor padrão de qualidade. É importante ressaltar que independentemente da espécie florestal manejada, de acordo com o local de produção, tipo e tamanho de recipiente e idade, o efeito da alternagem apresentará comportamentos similares aos das mudas de Eucalyptus urophylla x Eucalyptus grandis do presente estudo, porém, os valores médios de crescimento podem ser diferentes, devido às características particulares de cada espécie.

A densidade de plantas por área, embora seja um fator de importância econômica na produção de mudas concernente a espaço, requer uma identificação do seu limite, uma vez que ao ultrapassar o seu limiar pode gerar uma condição de inviabilidade econômica em função de limitação ao desenvolvimento satisfatório das plantas. Maior densidade de plantas por área leva ao aumento do autossombreamento, especialmente das folhas mais basais, desencadeando efeitos indesejados como diminuição da eficiência fotossintética em função da depleção da radiação fotossinteticamente ativa (RFA) à medida que se projeta à base da planta. Além da redução de RFA, o autossombreamento também é caracterizado pela alteração no balanço espectral da radiação, dado que a maior parte dos fótons nas bandas do azul e do vermelho é absorvida pelas folhas superiores não sombreadas (ROSATI; BADECK; DEJONG, 2001; SARLIKIOTI et al., 2011) e ambos os fatores, intensidade e qualidade de radiação, por sua vez, também interferem na ação dos fotorreceptores vegetais que regulam morfogênese vegetal.

\section{Conclusão}

Com base nos resultados, verificou-se que a redução da densidade realizada em diferentes momentos altera as características de crescimento das mudas. Considerando um ciclo de produção de 120 dias, recomenda-se a redução da densidade entre os 60 e 75 dias após a semeadura, uma vez que para o conjunto das características e índices avaliados, este foi o intervalo de tempo que propiciou, de maneira geral, as melhores características às mudas produzidas.

\section{Referências}

AGUIAR, F. F. A. et al. Crescimento de mudas de pau-brasil (Caesalpinia echinata Lam.), submetidas a cinco níveis de sombreamento. Revista Ceres, Lavras, v. 58, n. 6, p. 729-734, nov./dez. 2011.

ARAÚJO, M. M.; NAVROSKU, M. C.; SCHORN, L. A. Produção de sementes e mudas: um enfoque à silvicultura. Santa Maria: Editora UFSM, 2018. v. 1, 448 p.

ATAÍDE, G. M. et al. Efeito da densidade na bandeja sobre o crescimento de mudas de eucalipto. Revista Trópica Ciências Agrárias e Biológicas, Chapadinha, v. 4, n. 2, p. 21-26, maio/ago. 2010. 
BARRETTO, V. C. M. et al. Eficiência de uso de boro no crescimento de clones de eucalipto em vasos. Revista Scientia Forestalis, Piracicaba, v. 76, n. 1, p. 21-33, dez. 2007.

CALDEIRA, M. V. W. et al. Substratos alternativos na produção de mudas de Chamaecrista desvauxii. Revista Árvore, Viçosa, MG, v. 37, n. 1, p. 31-39, jan./fev. 2013.

CARNEIRO, J. G. Produção e controle de qualidade de mudas florestais. Curitiba: Universidade Federal do Paraná; Campo dos Goytacazes: Universidade Estadual do Norte Fluminense, 1995. 451 p.

CARON, B. O. et al. Eficiência de conversão da radiação fotossinteticamente ativa interceptada em fitomassa de mudas de eucalipto. Revista Árvore, Viçosa, MG, v. 36, n. 5, p. 833-842, set./out. 2012.

CHEN, M.; CHORY, J.; FANKHAUSER, C. Light signal transduction in higher plants. Annual Review Genetics, Palo Alto, v. 38, p. 87-117, dez. 2004.

CARVALHO, D. F. et al. Avaliação da evapotranspiração de referência na região de SeropédicaRJ, utilizando lisímetro de pesagem. Revista Brasileira de Agrometeorologia, Campina Grande, v. 14, n. 1, p. 108-116, jan./abr. 2006.

CHAVARRIA, G. et al. Índice de área foliar em canola cultivada sob variações de espaçamento e de densidade de Semeadura. Ciência Rural, Santa Maria, v. 41, n. 12, p. 2084-2089, dez. 2011.

COLOMBO, M. et al. Photosynthesis control: an underrated short-term regulatory mechanism essential for plant viability. Plant Signaling \& Behavior, [s. 1.], v. 11, n. 4, mar. 2016.

DAVIDE, A. C. et al. Fatores que afetam a qualidade de mudas destinadas aos projetos de restauração de ecossistemas florestais. In: DAVIDE, A. C. BOTELHO, S. A. (org.). Fundamentos e métodos de restauração de ecossistemas florestais: 25 anos de experiência em matas ciliares. 1. ed. Lavras: UFLA, 2015. p. 181-274.

DAVIDE, A. C.; SILVA, E. A. A. Produção de sementes e mudas de espécies florestais. 1. ed. Lavras, MG: Editora UFLA, 2008. 174 p.

DELARMELINA, W. M. et al. Uso de resíduo orgânico em substrato para produção de Chamaecrista desvauxii (Collad.) Killip var. latistipula (Benth.). Cerne, Lavras, v. 21, n. 3, p. 429-437, abr. 2015.

DIAS, B. A. S. et al. Análise econômica de dois sistemas de produção de mudas de eucalipto. Floresta e Ambiente, Seropédica, v. 18, n. 2, p. 171-177, abr./jun. 2011.

DICKSON, A.; LEAF, A. L.; HOSNER, J. F. Quality appraisal of while spruce and white pine seedling stock in nurseries. Forestry Chronicle, Quebec, v. 36, n. 1, p. 11-13, 1960.

FARIA, J. C. T. et al. Substratos à base de lodo de esgoto na produção de mudas de Senna alata. Comunicata Scientiae, Bom Jesus, v. 4, n. 4, p. 342-351, out./dez. 2013.

FERREIRA, D. F. Sisvar: a computer statistical analysis system. Ciência e Agrotecnologia, Lavras, v. 35, n. 6, p. 1039-1042, nov./dez. 2011.

FRAGOSO, V. et al. Functional specialization of Nicotiana attenuata phytochromes in leaf development and flowering time. Journal of Integrative Plant Biology, [s. 1.], v. 59, n. 3, p. 205224, mar. 2017.

GOMES, D. R. Lodo de esgoto como substrato para produção de mudas de Tectona grandis L. Cerne, Lavras, v. 19, n. 1, p. 123-131, abr. 2013.

GONÇALVES, J. L. M. et al. Produção de mudas de espécies nativas: substrato, nutrição, sombreamento e fertilização. In: GONÇALVES, J. L. M.; BENEDETTI, V. (ed.). Nutrição e fertilização florestal. Piracicaba: IPEF, 2000. p. 309-350.

JOSÉ, A. C.; DAVIDE, A. C.; OLIVEIRA, S. L. Produção de mudas de aroeira (Schinus terebinthifolius Raddi) para recuperação de áreas degradadas pela mineração de bauxita. Cerne, Lavras, v. 11, n. 2, p. 187-196, set. 2005. 
KUNZ, J. H. et al. Uso da radiação solar pelo milho sob diferentes preparos do solo, espaçamento e disponibilidade hídrica. Pesquisa Agropecuária Brasileira, Brasília, v. 42, n. 11, p. 1511-1520, nov. 2007.

LEIVAR, P.; MONTE, E. PIFs: systems integrators in plant development. Plant Cell, Rockville, v. 26, n. 1, p. 56-78, jan. 2014.

LIMA, J. D. et al. Efeitos da luminosidade no crescimento de mudas de Caesalpinia ferrea Mart. Ex Tul. (Leguminosae, Caesalpinoideae). Acta Amazonica, Manaus, v. 38, n. 1, p. 5-10, mar. 2008.

MONTEITH, J. L. Climate and the efficiency of crop production in Britain. Philosophical Transactions of the Royal Society of London, London, v. 281, p. 277-294, 1977.

PETTER, F. A. et al. Biochar como condicionador de substrato para a produção de mudas de eucalipto. Revista Caatinga, Mossoró, v. 25, n. 4, p. 44-51, out./dez. 2012.

REIS, E. R. et al. Período de permanência de mudas de Eucalyptus grandis em viveiro baseado em parâmetros morfológicos. Revista Árvore, Viçosa, MG, v. 32, n. 5, p. 809-814, set./out. 2008.

REIS, R. G. E. et al. Emergência e qualidade de mudas de Copernicia prunifera em função da embebição das sementes e sombreamento. Revista Caatinga, Mossoró, v. 24, n. 4, p. 43-49, out./ dez. 2011.

ROSATI, A.; BADECK, F. W.; DEJONG, T. M. Estimating Canopy Light Interception and Absorption Using Leaf Mass Per Unit Leaf Area in Solanum melongena. Annals of Botany, London, v. 88, n. 1, p. 101-109, jul. 2001.

SAIDELLES, F. L. F. et al. Casca de arroz carbonizada como substrato para produção de mudas de tamboril-da-mata e garapeira. Semina: Ciências Agrárias, Londrina, v. 30, n. 4, supl.1, p. 1731186, out./dez. 2009.

SARLIKIOTI, V. et al. How plant architecture affects light absorption and photosynthesis in tomato: towards an ideotype for plant architecture using a functional-structural plant model. Annals of Botany, London, v. 108, n. 6, p. 1065-1073, out. 2011.

SMITH, H. Sensing the light environment: the functions of the phytochrome family. In: KENDRICK, R. E.; KRONENBERG, G. H. M. (ed.). Photomorphogenesis in Plants. $2^{\text {nd }}$ ed. [S. l.]: Kluwer Academic Publishers, 1994. p. 377-416.

SOUZA, P. H. et al. Crescimento e qualidade de mudas de Senna macranthera (collad.) Irwin et Barn. em resposta à calagem. Revista Árvore, Viçosa, MG, v. 34, n. 2, p. 233-240, mar./abr. 2010.

SPERANDIO, H. V. et al. Qualidade de mudas de Eucalyptus urophylla $x$ Eucalyptus grandis produzidas em diferentes substratos. Engenharia Ambiental, Espírito Santo do Pinhal, v. 8, n. 4, p. 214-221, out./dez. 2011.

STEWART, D. W. et al. Canopy structure, lightinterception and photosynthesis in maize. Agronomy Journal, Madison, v. 95, n. 6, p. 1465-1474, nov. 2003.

TRAZZI, P. A. et al. Qualidade de mudas de Murraya paniculata produzidas em diferentes substratos. Floresta, Curitiba, v. 42, n. 3, p. 621-630, jul./set. 2012.

WENDLING, I.; DUTRA, L. F. Produção de mudas de eucalipto. 1. ed. Colombo: EMBRAPA Florestas, 2010. 184 p.

WESTON, E. et al. Light quantity controls leaf-cell and chloroplast development in Arabidopsis thaliana wild type and blue-light-perception mutants. Planta, Berlin, v. 211, n. 6, p. 807-815, nov. 2000 .

XAVIER, A.; SILVA, R. L. Evolução da silvicultura clonal de Eucalyptus no Brasil. Agronomía Costarricense, Viçosa, MG, v. 34, n. 1, p. 93-98, jan./jun. 2010. 